Research Article

\title{
Back-Calculation of Soil Modulus from PFWD Based on a Viscoelastic Model
}

\author{
Rui Zhang $\mathbb{D}^{1,2}$ Tianzeng Ren, ${ }^{2}$ Md Ashrafuzzaman Khan, ${ }^{3}$ Yusheng Teng, \\ and Jianlong Zheng ${ }^{1,2}$ \\ ${ }^{1}$ National Engineering Laboratory for Highway Maintenance Technology, Changsha University of Science \& Technology, \\ Changsha, Hunan 410114, China \\ ${ }^{2}$ School of Traffic and Transport Engineering, Changsha University of Science \& Technology, Changsha, Hunan 410114, China \\ ${ }^{3}$ Civil and Environmental Engineering, Texas A\&M University, College Station, TX 77840, USA
}

Correspondence should be addressed to Rui Zhang; zr@csust.edu.cn

Received 24 July 2019; Accepted 1 October 2019; Published 6 November 2019

Academic Editor: Venu G. M. Annamdas

Copyright (C) 2019 Rui Zhang et al. This is an open access article distributed under the Creative Commons Attribution License, which permits unrestricted use, distribution, and reproduction in any medium, provided the original work is properly cited.

To improve the accuracy of back-calculation of soil modulus using the portable falling weight deflectometer (PFWD), a viscoelastic method (VEM) overcoming the limitations of the conventional linear elastic method (LEM) was proposed. A quasi-static dynamic analysis technique of Laplace transformation and a modified Gauss-Newton optimization algorithm were adopted in the proposed method. The back-calculation program was compiled with MATLAB. The effectiveness of the proposed method was verified with the in situ plate load test (PLT) conducted on a highway embankment. In situ test results showed that a time lag existed between the peaks of deflection and load, and load-deflection curves were nonlinear, which indicated the viscoelastic nature of the soil. The back-calculated modulus using the LEM and VEM was higher than that using the PLT. In the case of low stiffness soil, the average error of back-calculation using the LEM and VEM was $53.1 \%$ and $14.8 \%$, respectively. However, for stiffer soil, the average error of back-calculation using the LEM and VEM method was $12.4 \%$ and $4.3 \%$, respectively. Moduli of backcalculation using LEM and VEM methods were used to perform flexible pavement analysis, which showed that with an $8 \%$ reduction of modulus, the pavement service life reduced by $25 \%$. More accurate estimation of modulus can save maintenance cost in the future.

\section{Introduction}

The Mechanistic-Empirical Pavement Design Guide and other existing pavement design guides use elastic modulus $(E)$ as the primary input parameter for subgrades. The soil modulus is typically determined by different laboratory tests or in situ nondestructive tests. The falling weight deflectometer (FWD) and plate load test (PLT) can be used to determine the stiffness of pavement, but these devices have some limitations when they are used during the construction of pavement subgrade. The FWD is not always applicable to the project site. And the PLT takes several hours so that it can slow down the construction process. These limitations can be overcome by conducting a test with a portable falling weight deflectometer (PFWD), a nondestructive and cost- effective tool used to determinate the soil modulus [1-6]. The soil modulus can be determined by the deflection profile and the back-calculation method.

Over the past decade, the PFWD as a portable and costeffective tool for determining the stiffness of foundation soil has gained much popularity $[1-3,7,8]$. Several static and dynamic back-calculation programs use the deflection profile to perform back-calculation analysis for determining the in situ elastic modulus. However, the modulus obtained from these programs may vary because of different assumptions, interactive technique calculation schemes, and material models [1, 4, 7, 9-14]. Stress and strain calculated from the available methods differ from the actual values in the pavement material and depend on the material model adopted for the pavement analysis [12, 15-17]. Although the 
base/subgrade is considered as a continuous, homogeneous, linear elastic materials in most of studies; in reality, they exhibit noncontinuous, nonhomogenous, anisotropic, viscous, plastic, and viscoelastic behaviors.

Based on the multilayered elastic theory, ASTM D585896 [18] provides a guideline for back-calculating the elastic modulus by deflections. Most researchers [1, 9, 12, 17, 19] used the linear elastic material model in their studies, as no additional guidance is available from the American Association of State Highway and Transportation Officials or the American Society of Testing Materials.

Modulus can be back-calculated by the available computer programs (e.g., MODULUS, MODCOMP, WESDEF, WESNET, MICHBACK 1.0, FWD-DYN, ELMOD, EVERCALC, WESDEF, CHEVDEF, ELSDEF, FDEDD1, SEARCH, FPEDDI, ISSEM4, PDADAL, and BISDEF). Most of these programs are based on the linear elastic layer theory, but their accuracy depends on the goodness of fit between the computed and measured deflections [15]. Assuming that the surface load is static and uniformly distributed, stress and strain are computed by these programs. Layers are linear elastic, isotropic, and homogeneous.

The PFWD test is dynamic. It has been observed that the linear elastic material model cannot accurately predict the response under dynamic load. Asli et al. [20] used a viscoelastic soil model to calculate the soil modulus. The plate/ soil system is represented by a single degree of freedom (SDOF) system. A least square algorithm was used as an error minimization technique. Elastic stiffness, the ratio of applied static load to measured deflection, can be estimated by the PLT. As the PFWD test is dynamic, the dynamic response of ground is affected by inertia and damping properties of media. Asli et al. [20] adopted a dynamic equilibrium equation in which the magnitude of applied load depends on acceleration, velocity, deformation, damping coefficient and stiffness of elastic medium, and applied load on the top of it. Based on the least-squares method, the elastic stiffness, damping coefficient, and equivalent mass were determined by the minimization technique, but the time parameter was omitted. Because of the lack of a time parameter, based on this method, the actual viscoelastic behavior could not be predicted. It was also assumed that the subgrade was considered as the Winkler foundation, a system of several individual springs. There are no internal connections between the springs, and the deformation of a certain point only depends on the pressure acting on the point. However, there is a direct transverse relationship between the soil particles, which restricts each other in the transverse direction. When the vertical load is applied to a certain point, it will deform vertically along with the adjacent soil particles and make a deflection basin instead of a single point deflection. Therefore, the soil medium considered as the Winkler spring system cannot predict the actual deflection shape.

There are two methods to analyze the dynamic response of viscoelastic system: quasi-static and dynamic methods. Amir and Javad [21] developed a dynamic analysis framework, which was used for any explicit/implicit time integral. Hudsadin and Yasothorn [22] used a dynamic half-space model for dynamic back-calculation of engineering soil properties based on the FWD data. In dynamic back-calculation, the structure of equation is complex, which is simplified by a numerical algorithm, that is, a time-consuming calculation method. Ameri et al. [23] adopted a layer-wise finite element equation for quasi-static analysis of laminated structures with embedded viscoelastic material whose constitutive behavior is represented by the Prony series. Ahmet et al. [24] studied the quasi-static behavior of viscoelastic Kirchhoff plates by the finite element method in transformed Laplace-Carsonspace. Compared with the dynamic method, the quasi-static method is simpler and less time-consuming.

Based on a viscoelastic model, a back-calculation method which incorporated a quasi-static dynamic response analysis method with elastic half-space theory was proposed first. The proposed method was then verified by field test results. Finally, a case study was conducted to analyze the importance of choosing an accurate soil modulus in pavement design.

\section{Field Studies}

The Hainan Wanning-Yangpu Highway is $163 \mathrm{~km}$ long. Approximately 2.4 million $\mathrm{m}^{3}$ high plasticity soils were excavated and used as filling materials for the construction of embankment in many sections of highway. The section between $\mathrm{K} 110+180$ and $\mathrm{K} 110+280$ was selected as a trial section in this study.

As shown in Figure 1(a), the cross section of embankment was divided into two parts in the vertical direction. One is $1.5 \mathrm{~m}$ high on the top of upper embankment, and the other is at the lower embankment. High plasticity soil was used to construct the lower embankment. The basic properties of soil in the trial section were determined by the laboratory tests. The natural moisture content, contents of fine-grained particle, liquid limit, and plastic limit were $29.1 \%, 60.3 \%, 54.0 \%$, and $28.5 \%$, respectively. The optimum moisture content and the maximum dry density determined by the standard compaction method (ASTM D698-12e2 [25]) were $17.3 \%$ and $1.76 \mathrm{~g} / \mathrm{cm}^{3}$, respectively. The high plasticity soil layers were compacted at a moisture content of $19 \%$ and its maximum dry density of $95 \%$. The slopes of both sides were covered with low plasticity soil to prevent surficial slope failure. The upper embankment was constructed with high plasticity soil mixed with $4 \%$ cement. The optimum moisture content and the maximum dry density determined by the modified compaction method (ASTM D1557 [26]) were $15.6 \%$ and $1.82 \mathrm{~g} \cdot \mathrm{cm}^{-3}$, respectively. The cementtreated soil layers were compacted at a moisture content of $17.3 \%$ and its maximum dry density of $93 \%$.

The modulus of high plasticity soil and cement-treated soil in compaction state was determined by the dynamic triaxial test (AASHTO T307-99 [27]) (Figure 2). Three samples were selected in this test. The average moduli of high plasticity soil and cement-treated soil were 19.6 MPa and 201.2 MPa, respectively. The coefficient of variation is about $5 \%$.

After the construction of lower embankment, the PFWD and PLT (Figure 3 ) were conducted in 10 specific locations 


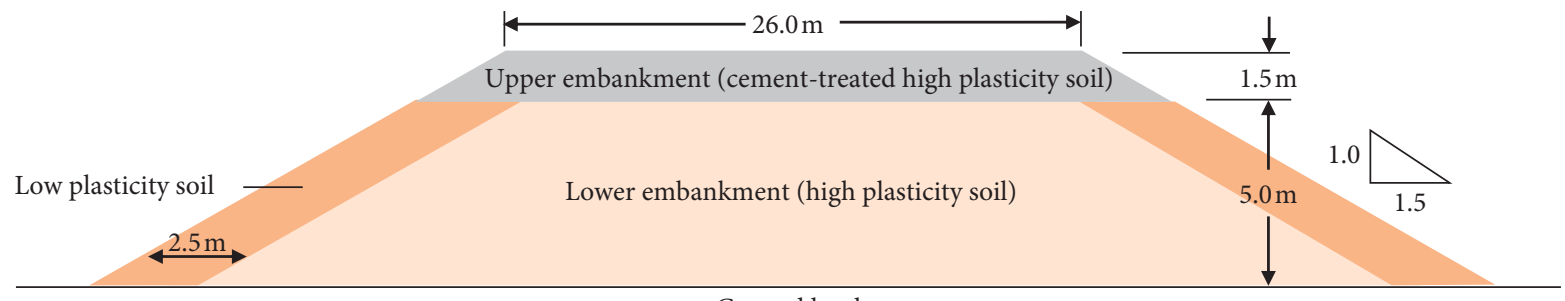

Ground level

(a)

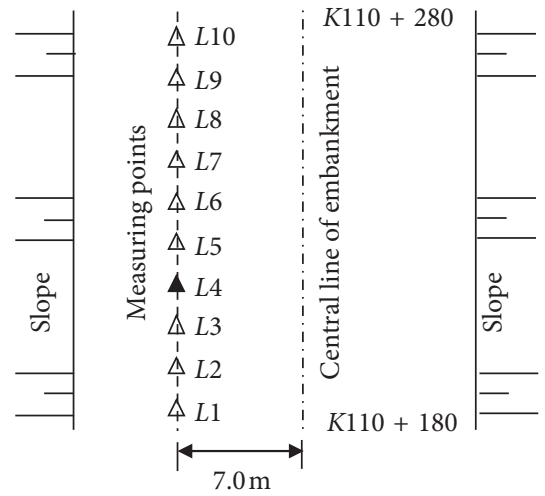

(b)

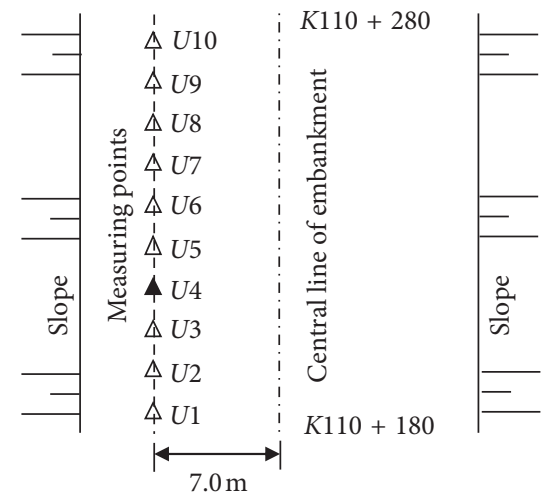

(c)

Figure 1: Embankment structure diagram and layout of measuring points. (a) Cross section of embankment. (b) Top of the lower embankment (elevation is $5.0 \mathrm{~m}$ from the ground level). (c) Top of the upper embankment (elevation is $6.5 \mathrm{~m}$ from the ground level).

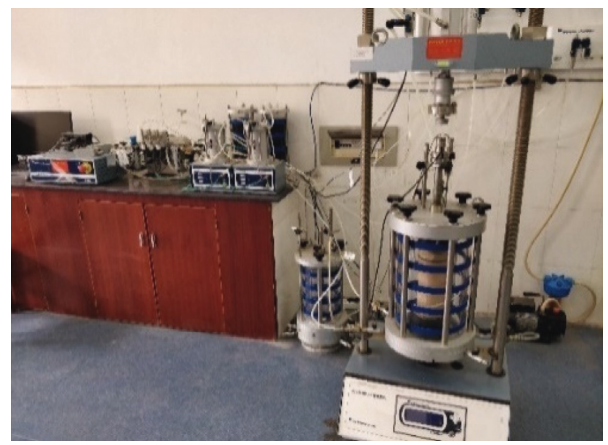

Figure 2: Dynamic triaxial test.

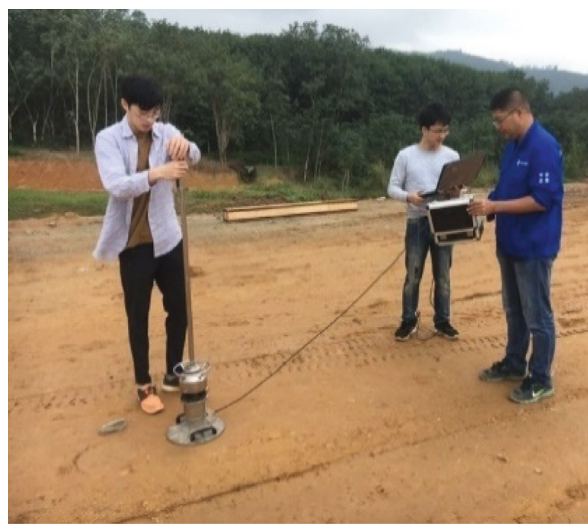

(a)

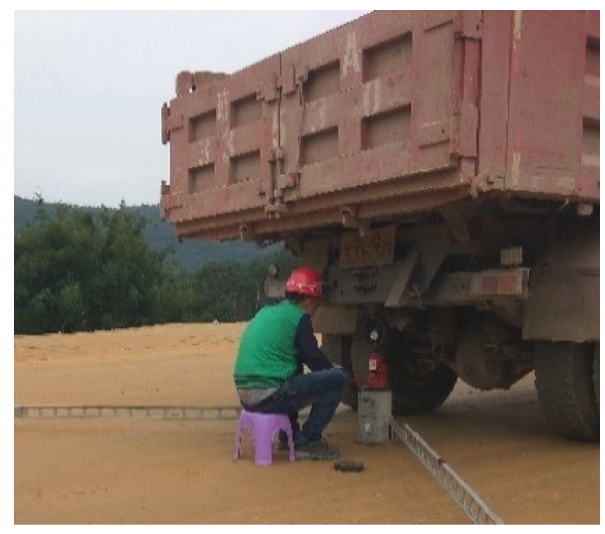

(b)

Figure 3: Field tests on the trial embankment of Wanning-Yangpu highway. (a) PFWD test. (b) PLT. 
(L1 to L10) and the spacing between two locations nearby was kept to $10 \mathrm{~m}$, as shown in Figure 1(b). Similarly, after the completion of upper embankment, the field tests were carried out on 10 locations (U1 to U10), as shown in Figure 1(c).

The primary parameters of PFWD equipment are as follows: the load plate radius is $0.15 \mathrm{~m}$; the load range is $1-15 \mathrm{kN}$; the load pulse shape is half-sine wave; the load sensor relative error is less than $1 \%$; the absolute error is $\pm 0.1 \mathrm{kN}$; the effective test accuracy of deflection sensor is $1 \mu \mathrm{m}$; the maximum test range is $2200 \mu \mathrm{m}$; and the data acquisition period is $0 \sim 60 \mathrm{~ms}$. The PFWD test methods and procedures were carried out according to ASTM E2583-07 [28]. The PLT was conducted in accordance with relevant provisions of the ASTM D1195 [29].

The load-deflection and time-history curves obtained from these locations were similar in nature, and the data obtained from the L4 and U4 points were selected for further analysis. The field test results obtained from the top of lower and upper embankments are shown in Figures 4 and 5, respectively.

The time lag between the peaks of deflection and load for the low stiffness soil can be observed from Figure 4(a). Due to the viscoelastic behavior of high plasticity soil, the peak deformation was $3 \mathrm{~ms}$ later than the peak of load. When the applied load reaches the peak, the corresponding deformation is lower than the peak value; When the deformation reaches the peak, the corresponding load is lower than the maximum load. The magnitude of load curve started to decrease after reaching the peak, but the magnitude of deformation curve still increased to the peak during the lag time. Nonlinear behavior and hysteresis loops were observed in the load-deflection curve, as shown in Figure 4(b). Therefore, the deformation hysteresis effect of high plasticity soil under the impact load is significant.

The PFWD and PLT were carried out on the upper embankment surface of $\mathrm{K} 110+180 \sim \mathrm{K} 110+280$ section to study the applicability of VEM to the stiffer soil embankment test. The PFWD test results at U4 are shown in Figures 5(a) and 5(b). Compared with Figures 4(a) and 4(b), due to the increase of soil modulus, the deformation hysteresis effect and load-deflection hysteresis loop were significantly reduced, but they still existed, thus causing an error in the LEM back-calculation.

In the existing conventional method, it is assumed that to back-calculate the elastic modulus by the PFWD, the relationship between load and deformation is approximately linear. The Boussinesq solution of elastic half-space in equation (1) was used to calculate the soil modulus:

$$
E=\frac{\pi R}{2} \frac{p\left(1-\mu^{2}\right)}{w},
$$

where $E$ is the soil modulus value (MPa), $p$ is the peak load plate pressure (MPa), $R$ is the radius of the load plate $(\mathrm{m})$, Poisson's ratio $\mu$ is 0.35 , and $w$ is the peak vertical deflection $(\mathrm{mm})$.

For the top of lower embankment (L1-L10), the comparison of the LEM modulus with the measured modulus are shown in Figure 6(a). The maximum, minimum, and average values of the LEM and measured moduli are $27.5 \mathrm{MPa}$ and 18.4 MPa, 24.5 MPa and 15.1 MPa, 26.0 MPa and 17.0 MPa, respectively. For the lower embankment, the average absolute and relative errors are $9.0 \mathrm{MPa}$ and $53.1 \%$, respectively. The measured and back-calculation results of all 10 measuring points on the top of upper embankment (U1-U10) are shown in Figure 6(b). The maximum, minimum, and average values of the LEM and measured moduli are $238.1 \mathrm{MPa}$ and $213.2 \mathrm{MPa}, 208.2 \mathrm{MPa}$ and $184.5 \mathrm{MPa}$, 221.8 MPa and 197.3 MPa, respectively. For the upper embankment, the average absolute error is $24.5 \mathrm{MPa}$, and the average relative error is $12.4 \%$.

The loading frequencies of the PFWD, dynamic triaxial and PLT are about $4 \mathrm{~Hz}, 1 \mathrm{~Hz}$, and $0 \mathrm{~Hz}$, respectively. When the soil is loaded at low frequency, the pulse duration is longer and the behavior of soil is mainly controlled by its quasi-static stiffness. However, when the pulse duration is short and the frequency increases, the soil behavior is mainly controlled by inertia, which weakens the dynamic response amplitude of soil. Only the peak values of load and vertical deflection were considered in equation (1), which generated a higher value of elastic modulus than the modulus obtained from the dynamic triaxial and PLT.

\section{Proposed Moduli Back-Calculation Method Based on a Viscoelastic Model}

The LEM is not accurate. Therefore, it is necessary to establish a simple method for back-calculation modulus that can better reflect the nonlinear dynamic response characteristic of high plasticity soil embankments under an impact load.

3.1. Selected Viscoelastic Theoretical Model. It is well known that under a sinusoidal dynamic load, the strain of viscoelastic material changes periodically, and the strain response lags behind the stress response. The viscoelastic theoretical model has been commonly applied to dynamic response analysis of asphalt pavement under the traffic load. The deformation hysteresis effect of a high plasticity soil embankment under impact load is similar to the mechanical behavior of viscoelastic materials mentioned earlier. Therefore, based on the viscoelastic constitutive model, a high plasticity soil modulus back-calculation method was established in this research.

The Kelvin and Maxwell viscoelastic models are relatively simple, whereas the three-parameter solid model, Burgers model, and generalized Maxwell model are more complex. The Maxwell model is a series of spring-dampers that are primarily used to simulate the stress relaxation process of viscoelastic materials. The three-parameter solid model, Burgers model, and a generalized Maxwell model are constructed by a spring-damper parallel and series. The calculated parameters were incorporated to better describe the viscoelastic and residual deformation properties of material under dynamic load. However, the multiparameter model greatly increases the difficulty and iteration time of the back-calculation, but the results may not converge. In the 


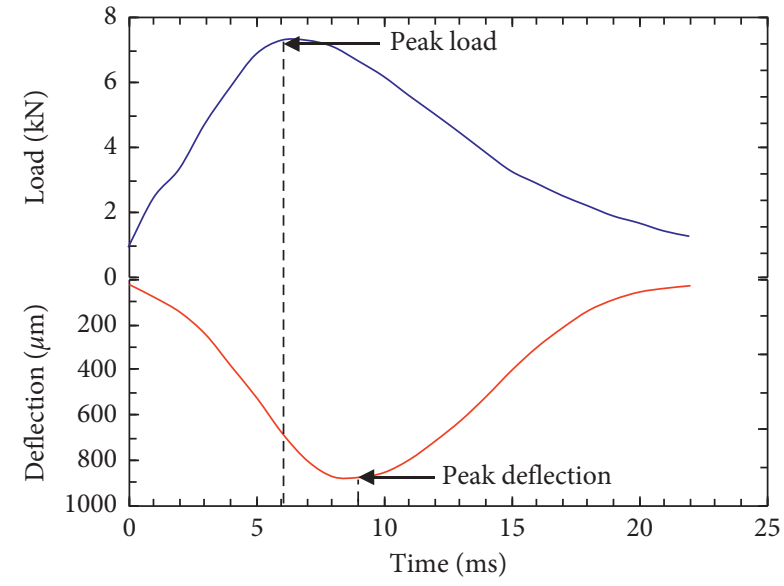

(a)

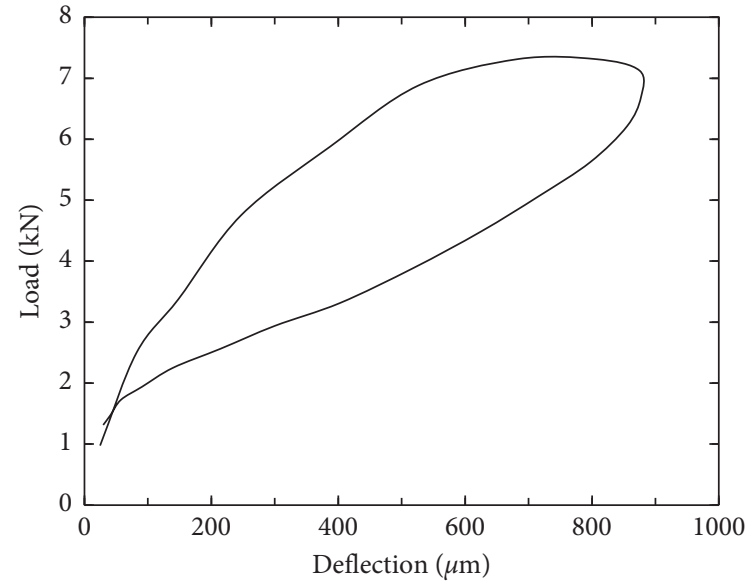

(b)

FIgURE 4: PFWD results for L4. (a) Load and deflection time-history curve. (b) Load-deflection curve.

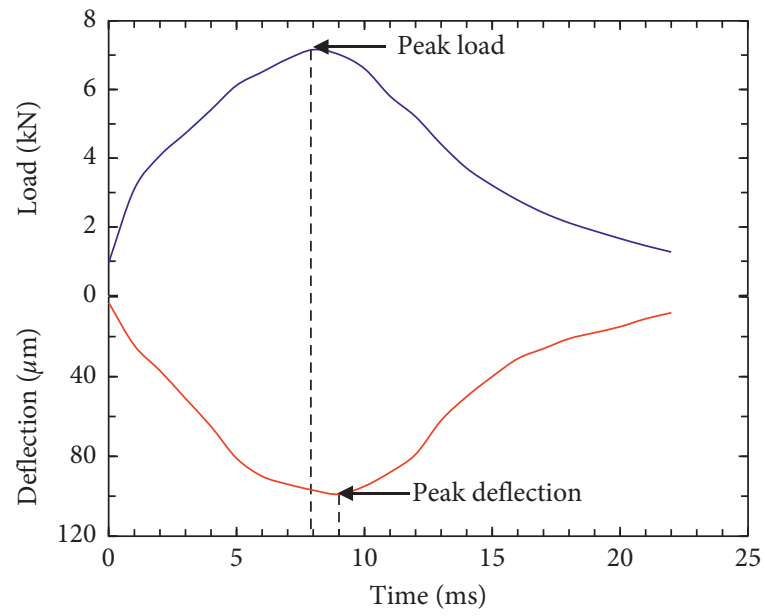

(a)

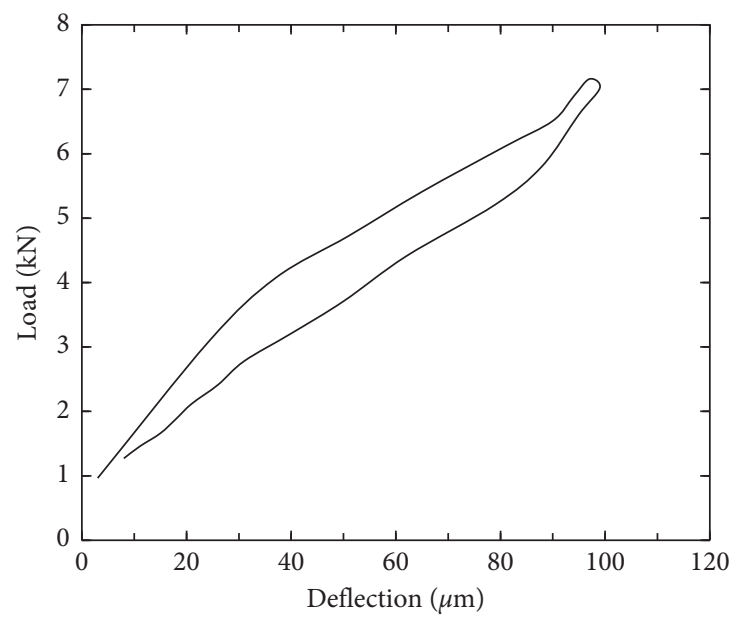

(b)

FIgURE 5: PFWD results for U4. (a) Load and deflection time-history curve. (b) Load-defection curve.

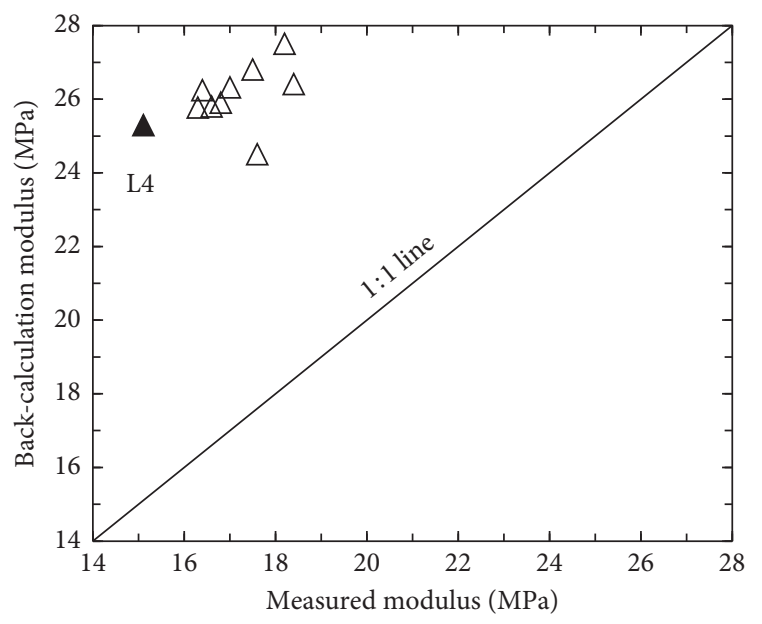

(a)

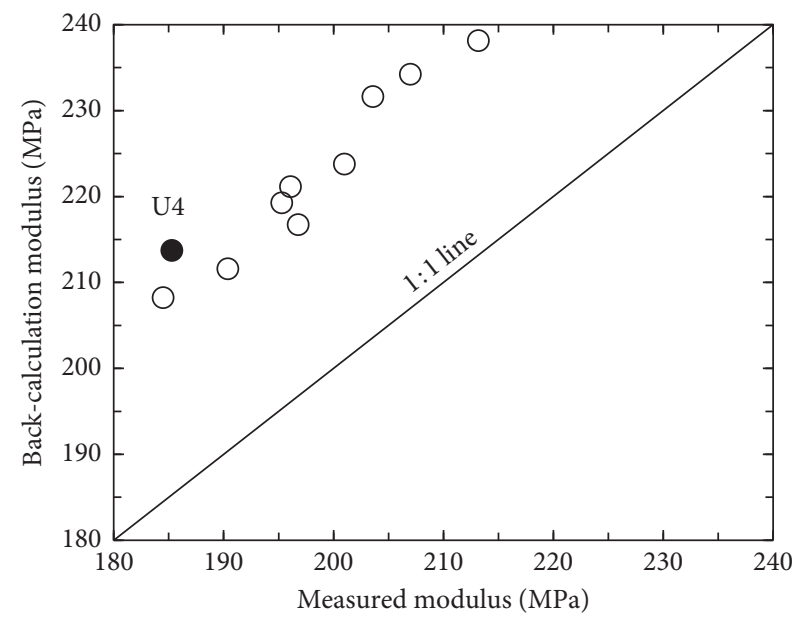

(b)

Figure 6: Comparison of back-calculated moduli using LEM and measured moduli using PLT. (a) Results of L1-L10. (b) Results of U1-U10. 
PFWD test, the loading and unloading time of drop hammer impact is very short so that the plastic deformation cannot occur in time. The vertical deformation measured by PFWD is mainly rebound deformation. However, only the recoverable deformation was used to determine the elastic modulus, and the permanent deformation part was eliminated by the repeated dropping of the hammer. Therefore, it is not necessary to consider the residual deformation or adopt the complicated multiparameter viscoelastic model to calculate the high plasticity soil modulus.

In this study, the Kelvin model was selected, and its concise structure was conducive to an efficient iteration of subsequent MATLAB program. The mechanical response of subgrade can be described by this model to meet the accuracy requirements.

The Kelvin model, a viscoelastic model, was composed of a spring-damper in parallel. It is simple in form and easy to iterate efficiently. Its mathematical description is as follows:

$$
\sigma=E \varepsilon+\eta \frac{\mathrm{d} \varepsilon}{\mathrm{d} t}
$$

where $\sigma$ is the stress, $\varepsilon$ is the strain, $E$ is the elastic modulus, and $\eta$ is the viscosity coefficient.

The load-time curve obtained from the PFWD impact load can be considered as a semisine curve. Assuming that the mathematical expression of curve is $\bar{\sigma} \sin (\omega t)$, equation (3) was obtained by substituting $\bar{\sigma} \sin (\omega t)$ into equation (2) and ignoring the rapid attenuation index items associated with time $t$ :

$$
\left(\frac{\sigma}{\bar{\sigma}}\right)^{2}-2 \cos (\delta)\left(\frac{\sigma}{\bar{\sigma}}\right)\left(\frac{\varepsilon}{\bar{\varepsilon}}\right)+\left(\frac{\varepsilon}{\bar{\varepsilon}}\right)^{2}=\sin ^{2}(\delta),
$$

where $\bar{\sigma}$ is the stress amplitude, $\bar{\varepsilon}$ is the strain amplitude, $\delta$ is the phase difference, and $\tan (\delta)=\eta \omega / E$.

According to equation (3), the stress-strain curve under the action of loading and unloading conditions can be obtained, as shown in Figure 7 . It could be seen that when the viscosity coefficient was introduced, the loading stress first reached the maximum value, and the corresponding strain did not reach the maximum. However, the maximum strain was observed during the unloading process due to the hysteresis. The stress-strain curve is very similar to the PFWD-measured load-deflection curve, as shown in Figure 4(b). Therefore, the Kelvin model was adopted to analyze the dynamic response of high plasticity soil under impact load.

3.2. Quasi-Static Back-Calculation Method. The dynamic and quasi-static methods were used for simulating dynamic response analysis of elastic systems under dynamic loading.

In the dynamic back-calculation [20], combined the motion differential equation of axisymmetric space problem in the cylindrical coordinate system with the physical equation of stress expressed by displacement, the Navier dynamic equation can be obtained. The viscoelastic theory model was introduced into the Navier dynamic equation, and the explicit solution of vertical deflection was derived by Laplace and Hankel back-calculation. The complex mixed-

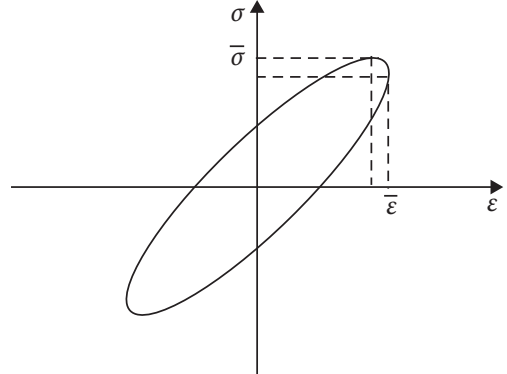

Figure 7: Stress-strain curve of Kelvin model.

boundary-value problem was also considered. Since the structure of implicit partial differential equations was complicated in back-calculation, time-consuming numerical algorithms were adopted to simplify it.

For this research, the quasi-static back-calculation method is to take the explicit solution of vertical deflection on the surface of the elastic half-space body under the static load as Laplace transformation and to replace the elastic parameters in the equation with viscoelastic operators. In this method, the dynamic load data were used to calculate the static parameters. Subsequent back-calculation results verified that the quasi-static method met the requirements for back-calculation of high plasticity soil embankments. Therefore, the modulus calculated by this method and the PFWD dynamic load data described in this study is static modulus, which is consistent with the static modulus measured by the PLT.

The vertical deflection on the surface of elastic half-space body under the action of an axial symmetric load was calculated as follows:

$$
w(r)=\frac{2\left(1-\mu^{2}\right)}{E} \int_{0}^{\infty} J_{0}(\xi r) \bar{p}(\xi) d \xi,
$$

where $J_{0}(x)$ is the zero-order Bessel function, $\bar{p}(\xi)$ is the zero-order Hankel integral transformation of the load for PFWD rigid bearing plate, $\bar{p}(\xi)=p R \sin (\xi R) / 2 \xi ; p$ is the load plate pressure $\left(\mathrm{kN} \cdot \mathrm{m}^{-2}\right), R$ is the radius of the load plate $(\mathrm{m})$, and $r$ is the radial distance from the load center of calculation point $(\mathrm{m})$.

After the Laplace transformation of equation (4) was performed, the viscoelastic operator was used to replace the elastic modulus, and the PFWD load function $\bar{p}(\xi)$ was substituted into the equation for inverse Laplace transformation. Since the Poisson ratio, which changes less, has little influence on the calculation result, it was not considered in the calculations. The vertical explicit deflection equation of viscoelastic half-space surface under the action of the PFWD rigid loading plate was obtained as follows:

$$
\begin{aligned}
w(r, t) & =L^{-1}(\bar{w}(r, s)) \\
& =\frac{\left(1-\mu^{2}\right) F}{\pi \cdot E(s) \cdot R}\left(1-e^{-(E / \eta) t}\right) \int_{0}^{\infty} \frac{J_{0}(\xi r) \sin \xi R}{\xi} d \xi,
\end{aligned}
$$

where $E(s)=E+\eta s$ is the viscoelastic operator; $F$ is the concentrated force generated by the PFWD (KN) acting on 
the surface of the measuring point, which is obtained by the load time-history curve; $R$ and $r$ have the same meaning as equation (4); and $s$ is the Laplace transformation parameter of time $t$.

In equation (5), it is shown that when $t=0$, the vertical deflection is 0 . As $t$ approaches infinity, the vertical deflection is equal to the vertical deflection calculated by the traditional elastic half-space theory. The viscosity coefficient $\eta$ generally ranges from 0 to 1 , which limits the overall vertical deformation. It also causes the theoretically calculated peak value of deflection time-history to reduce and the phase to extend to the right.

\subsection{Establishment of Modulus Back-Calculation Procedure.} As shown in equation (5), the back-calculation parameters are modulus value $E$ and the viscosity coefficient $\eta$. Due to the complexity of equation (5), it is difficult to obtain the analytic solution to determine the back-calculation parameters. Therefore, the least square method was used in this study, namely the optimization algorithm iterated by

$$
\min (\Delta)=K \sum_{i=1}^{n}\left[W\left(t_{i}\right)-w\left(t_{i}, \boldsymbol{\beta}\right)\right]^{2},
$$

where $K$ is the accuracy control parameter, $W$ is the measured value of vertical deflection $(\mathrm{mm}), \boldsymbol{\beta}=(E, \eta)$ is the back-calculation parameter vector, and $i$ and $n$ are the data number and the total data number of deflection time-history measured by PFWD, respectively.

The modified Gauss-Newton method was used in the iterative process, that is, when $\min (\Delta)=f(\boldsymbol{\beta})$, equation (6) was transformed into equation (7) as follows:

$$
f(\boldsymbol{\beta})=K r^{T}(\boldsymbol{\beta}) r(\boldsymbol{\beta}),
$$

where $r(\boldsymbol{\beta})$ is the residual column vector of measured and theoretical values.

In the calculation, the initial calculation parameter vector $\boldsymbol{\beta}_{0}$ was first set. An initial modulus and a viscous coefficient value are generally set by experience. The next iteration parameter vector was determined by

$$
\boldsymbol{\beta}_{k+1}=\boldsymbol{\beta}_{k}+\lambda_{k} \mathbf{A}_{k}
$$

where $k$ is the iteration number, $k=0,1,2, \ldots$, and $\lambda_{k}$ is the step size, which can be $0.01 \sim 0.05$ by experience.

In order to improve the iteration speed, the optimal value of step size can also be searched by $\min \left(\boldsymbol{\beta}_{k}+\lambda_{k} \mathbf{A}_{k}\right)$, where $\mathbf{A}_{k}$ calculated by $\mathbf{A}_{k}=-\left(\mathbf{J}_{r}^{T} \mathbf{J}_{r}\right)^{-1} \mathbf{J}_{r}^{T} r\left(\boldsymbol{\beta}_{k}\right)$ is the direction vector and $\mathbf{J}_{r}$ is the Jacobi matrix when $\boldsymbol{\beta}=\boldsymbol{\beta}_{k}$.

The iterative cycle process was controlled by

$$
\left|\left(\boldsymbol{\beta}_{k+1}-\boldsymbol{\beta}_{k}\right)^{T} \cdot\left(\begin{array}{l}
1 \\
0
\end{array}\right)\right| \leq \varepsilon,
$$

where $T$ is the vector transpose and $\varepsilon$ is the iterative control parameter.

The final iteration value $\boldsymbol{\beta}_{g}$ was calculated by equation (10), that is, the optimal back-calculation value of modulus and viscosity coefficient.

$$
\boldsymbol{\beta}_{g}=\frac{\left(\boldsymbol{\beta}_{k+1}+\boldsymbol{\beta}_{k}\right)}{2} .
$$

Because the least-square optimization algorithm is based on the back-calculation result of global extremum in the function definition domain, the results may be quite different from the actual situation. Therefore, when the backcalculation program was compiled, the specific conditions of high plasticity soil modulus detected by PFWD were dealt with as follows. Since the data collection period is $0 \sim 60 \mathrm{~ms}$, the PFWD will vibrate on the rubber block, thus driving the bearing plate to have a small jump. Therefore, the $0 \sim 25 \mathrm{~ms}$ peak waveform data were taken. The calculation point was $r=0 \mathrm{~m}$, that is, the center of load acting surface. The accuracy control parameter $K$ is 0.5 , and the iterative control coefficient $\varepsilon$ is 0.01 . These two control values can be adjusted according to the accuracy requirements.

In addition, equation (8) was revised into equation (11) to control the weight of the back-calculation modulus. When the phase of calculated deflection to time-history is greater than the measured deflection time-history, or the calculated deflection peak value is less than the measured deflection value, the iteration of parameter $\eta$ will stop and the iteration of parameter $E$ will continue because the iteration fails to meet the requirements of equation (9).

$$
\boldsymbol{\beta}_{k+1}=\boldsymbol{\beta}_{k}+\lambda_{k} \mathbf{A}_{k} \mathbf{B}
$$

where $\mathbf{B}$ is the iterative weight control vector calculated by

$$
\mathbf{B}= \begin{cases}(1,1), & E\left(\boldsymbol{\beta}_{k}\right) \leq \gamma, \\ (1,0), & E\left(\boldsymbol{\beta}_{k}\right)>\gamma,\end{cases}
$$

where $E\left(\boldsymbol{\beta}_{k}\right)$ is the limit condition of peak error of measured deflection and calculated deflection $\left(E\left(\boldsymbol{\beta}_{k}\right)=\mid W_{\max }-\right.$ $\left.w_{\max }\left(\boldsymbol{\beta}_{k}\right) \mid\right), W_{\max }$ is the measured deflection peak $(\mathrm{mm})$, $w_{\max }\left(\boldsymbol{\beta}_{k}\right)$ is the calculated deflection peak $(\mathrm{mm})$, and $\gamma$ is the deflection peak error control parameter $(\mathrm{mm})$, which can be adjusted to change the accuracy of the final back-calculation according to the users' requirement. In this study, $\gamma=0.002 \mathrm{~mm}$.

After obtaining the back-calculation solution, the deflection was calculated and the calculation accuracy was evaluated by

$$
R^{2}=1-\frac{\sum_{i=1}^{n}\left[W\left(t_{i}\right)-w\left(t_{i}, \boldsymbol{\beta}_{k}\right)\right]^{2}}{\sum_{i=1}^{n} W\left(t_{i}\right)^{2}-\left(\left(\sum_{i=1}^{n} W\left(t_{i}\right)\right)^{2} / n\right)},
$$

where $R^{2}$ is the accuracy factor.

According to the method proposed in this study, the back-calculation program of soil modulus considering the effect of deformation hysteretic effect under impact load was compiled by MATLAB. It applies to both FWD and PFWD back-calculations. The proposed back-calculation process is shown in Figure 8.

\section{Verification of the Proposed Modulus Back- Calculation Method}

The load-deflection time-history data obtained from L1-10 and U1-10 were used to back-calculate the elastic modulus 


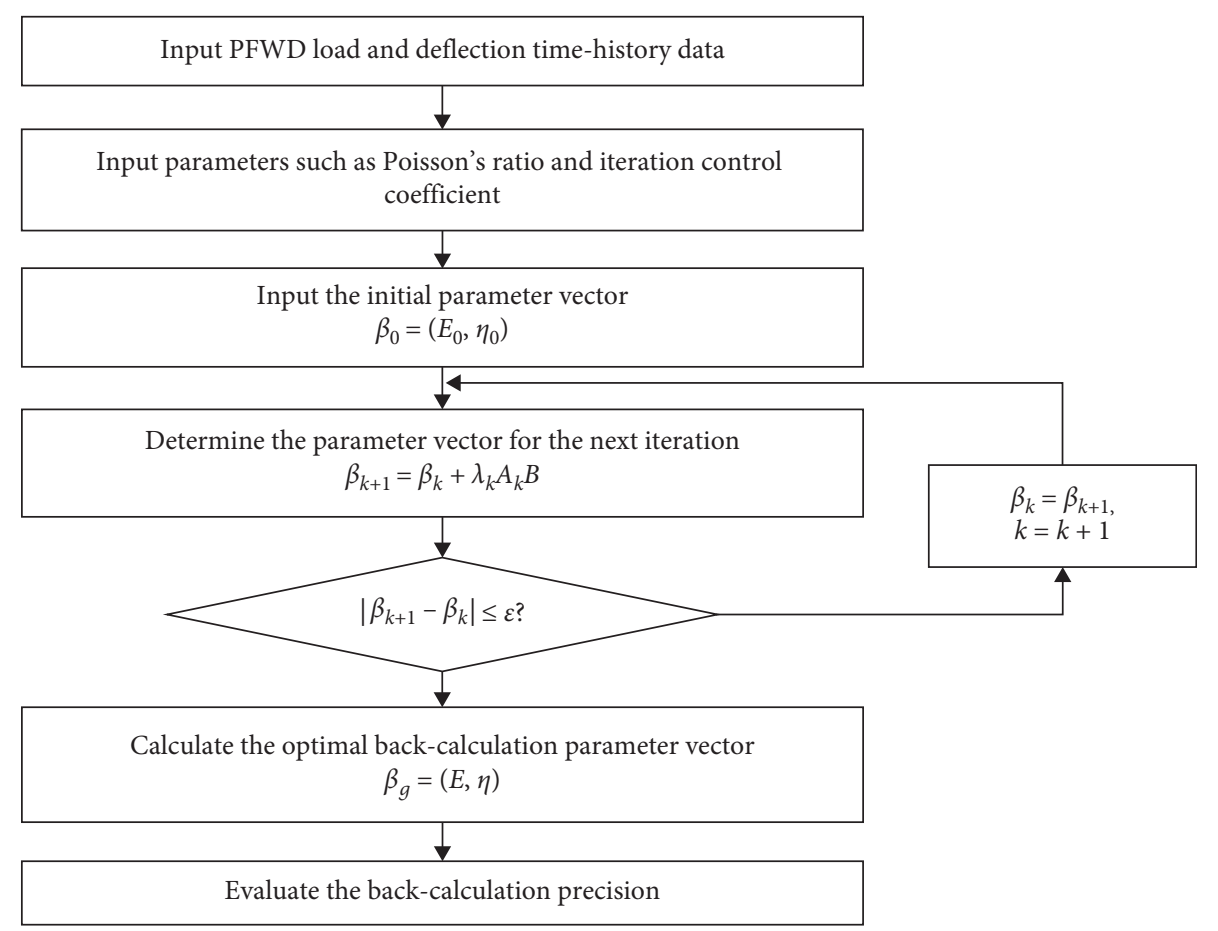

FIGURE 8: Proposed back-calculation method.

with the VEM. The LEM and VEM were used to obtain the back-calculated modulus for these locations which was further compared with that measured by the PLT. The moduli of L4 and U4 obtained from different methods are also listed in Table 1. The estimated moduli for the untreated (lower embankment) and cement-treated (upper embankment) soils are 17.2 $\mathrm{MPa}$ and $192.3 \mathrm{MPa}$, respectively. The proposed VEM method overestimated the moduli of untreated and treated soils by $13.9 \%$ and $3.8 \%$, respectively. However, the conventional LEM overestimated the moduli of untreated and treated soils by $67.5 \%$ and $15.3 \%$, respectively. The VEM can greatly reduce the error in estimating the modulus as it can accurately predict the time required to reach the peak deflection obtained from the PFWD. Compared with the actual in situ data, the moduli obtained from the VEM and LEM were used to regenerate the deflection-time-history data.

In Figure 9, a comparison of the time-history curve of L4 is shown. It can be seen that the deflection time-history calculated by the VEM is in good agreement with the measured deflection time-history. According to equation (13), the calculation accuracy coefficients measured by the VEM and LEM are 0.935 and 0.693 , respectively.

In Figure 10, a comparison of the time-history curve of $\mathrm{U} 4$ is shown. It can be seen that the deflection time-history calculated by the VEM and LEM are in good agreement with the measured deflection time-history. For the cementtreated soil, the calculation accuracy coefficients measured by the VEM and LEM are 0.945 and 0.826 , respectively. Under the same loading condition, for the stiffer soil, the vertical deflection is smaller, which reduces the effect of filling viscosity. Therefore, the moduli obtained from LEM and VEM are very close to each other.

Back-calculated moduli of all 10 test points on the top of lower embankment performed by the VEM are shown in Figure 11(a). The maximum, minimum, and average backcalculation modulus values of 10 test points are $21.5 \mathrm{MPa}$, 17.2 $\mathrm{MPa}$, and 19.5 $\mathrm{MPa}$, respectively. The modulus obtained from the VEM is closer than that obtained from the LEM. The average absolute error is only $2.5 \mathrm{MPa}$, and the average relative error is $14.8 \%$. It has been proven that the quasidynamic analysis method can be used to calculate the static parameters according to the dynamic response of embankments under impact load (load-deflection time-history data). The static modulus measured by VEM is closer to that measured by the PLT.

In Figure 11(b), the measured and back-calculated results of all 10 test points on the top of the $\mathrm{K} 110+180 \sim \mathrm{K} 110+280$ trial section of upper embankment are shown. The statistical results show that the maximum, minimum, and average modulus values of 10 test points back-calculated by the VEM are 220.6 MPa, 191.6 MPa, and 205.8 $\mathrm{MPa}$, respectively. The average absolute error is $8.5 \mathrm{MPa}$, and the average error is only $4.3 \%$. It is shown that when the soil modulus is high, the average relative errors of moduli back-calculated by the VEM and LEM are both reduced, but the former is smaller.

According to the field test results of trial section of high plasticity soil embankment, the relative errors of back-calculated modulus by the VEM and measured modulus are both within $15 \%$ in the lower and upper embankments with low stiffness and stiffer soils, respectively. Therefore, the 
TABLE 1: Comparison of the LEM, VEM, and measured results.

\begin{tabular}{|c|c|c|c|c|c|c|}
\hline \multirow{2}{*}{ Measuring point } & \multicolumn{3}{|c|}{$\mathrm{L} 4$} & \multicolumn{3}{|c|}{$\mathrm{U} 4$} \\
\hline & LEM & VEM & Measured & LEM & VEM & Measured \\
\hline Modulus (MPa) & 25.3 & 17.2 & $15.1^{\mathrm{a}}$ & 213.7 & 192.3 & $185.3^{\mathrm{a}}$ \\
\hline$R^{2}$ & 0.693 & 0.935 & NA & 0.826 & 0.945 & NA \\
\hline \multicolumn{7}{|l|}{ Load } \\
\hline Peak (kN) & NA & NA & $7.313^{\mathrm{b}}$ & NA & NA & $7.160^{\mathrm{b}}$ \\
\hline Time (ms) & NA & NA & $6^{\mathrm{b}}$ & NA & NA & $8^{\mathrm{b}}$ \\
\hline \multicolumn{7}{|l|}{ Deflection } \\
\hline Peak $(\mu \mathrm{m})$ & 845 & 872 & $877^{\mathrm{b}}$ & 98 & 99 & $99^{\mathrm{b}}$ \\
\hline Time (ms) & 6 & 9 & $9^{\mathrm{b}}$ & 8 & 9 & $9^{\mathrm{b}}$ \\
\hline
\end{tabular}

Note: $R^{2}$ is the accuracy coefficient, which is calculated by equation (13); a is the test result obtained from PLT; $\mathrm{b}$ is the test result obtained from PFWD.

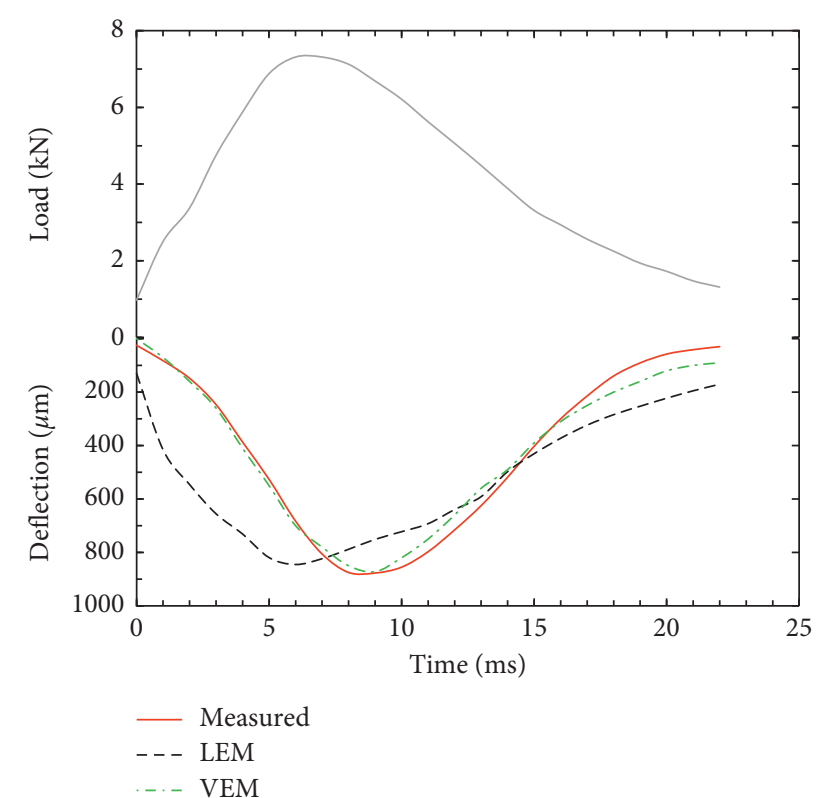

FIGURE 9: Comparison of measured and back-calculated deflectiontime curves of L4.

back-calculation modulus measured by the VEM can be used as the parameter for pavement design.

\section{Case Study}

The soil modulus of upper embankment obtained from the VEM is statistically lower than that obtained from the LEM. Ignoring the viscoelastic nature of embankment may lead to the overestimation of stiffness, which has a significant influence on the design life of a pavement. A hypothetical case study was performed to analyze the effect of soil modulus on the design life of a flexible pavement consisting of an asphalt layer, base layer, and subgrade (Figure 12). Rutting, fatigue, and low-temperature cracking are the principal types of diseases that should be considered for the design of flexible pavement [30]. Typical modulus values obtained from the literature were used for the asphalt and base layers. Soil moduli of upper embankment obtained from both the LEM and VEM were used as subgrade moduli for comparison.

Considering the soil moduli obtained from the LEM and VEM, pavement analyses were performed with FPS 21

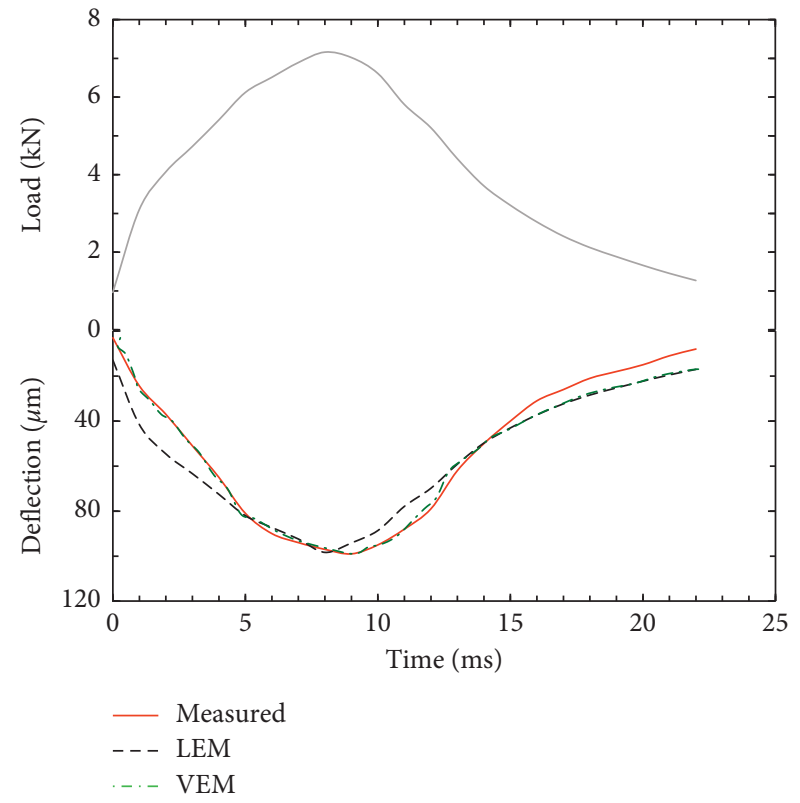

FIGURE 10: Comparison of measured and back-calculated deflection-time curves of U4.

software to compare the cracking and rutting life of flexible pavement. A low-volume road expected to carry 0.8 million equivalent standard axle loads (ESALs) throughout its design life of 20 years was considered. Design data used for the pavement analysis are listed in Table 2.

5.1. Fatigue Cracking Criteria. The fatigue cracking of flexible pavement can be determined by the following equation:

$$
N_{f}=f_{1}\left(\varepsilon_{t}\right)^{-f_{2}}\left(E_{A}\right)^{-f_{3}},
$$

where $N_{f}$ is the allowable number of load repetitions; $\varepsilon_{t}$ is the horizontal tensile strain acting at the bottom of asphalt layer; $E_{A}$ is the elastic modulus of the asphalt layer; and $f_{1}, f_{2}$, and $f_{3}$ are constant values proposed by the agencies that are listed in Table 3.

Cracking life determined in terms of traffic volume depends on the thickness of base layer, as shown in Figure 13. 


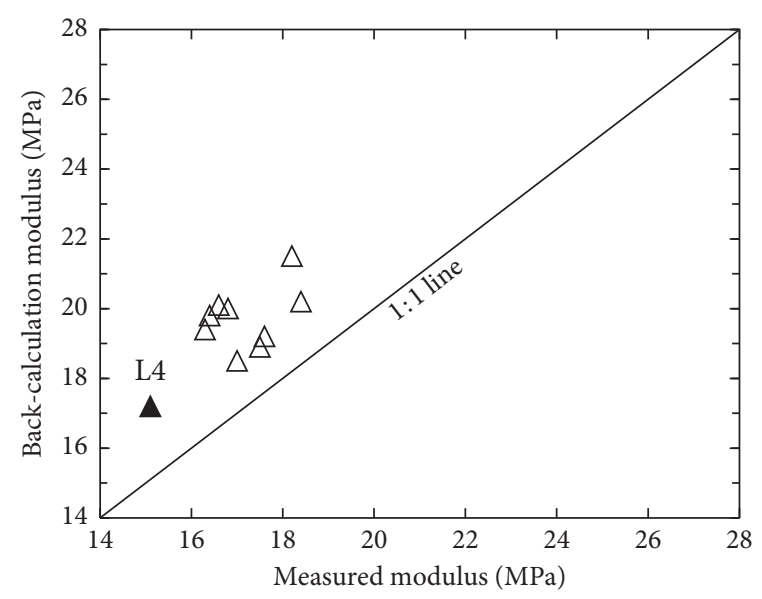

(a)

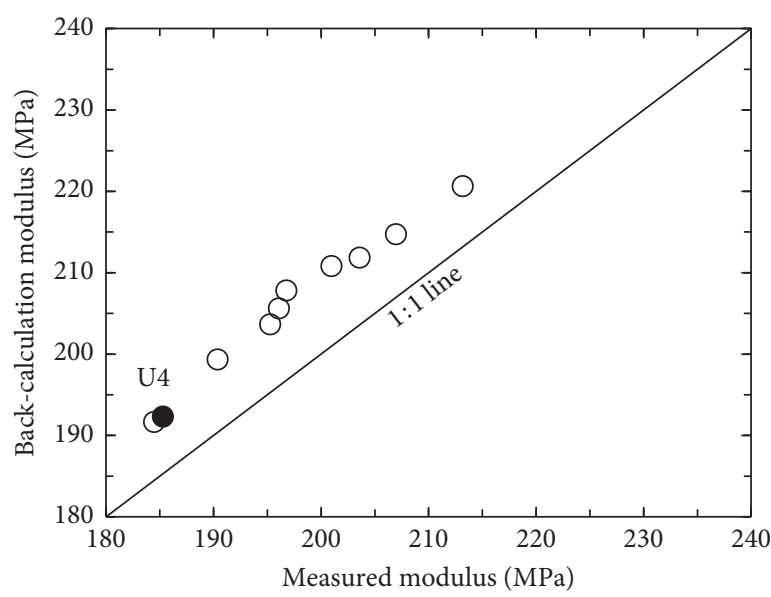

(b)

FIGURE 11: Comparison of back-calculated moduli using VEM and measured moduli using PLT. (a) Results of L1-L10. (b) Results of U1-U10.

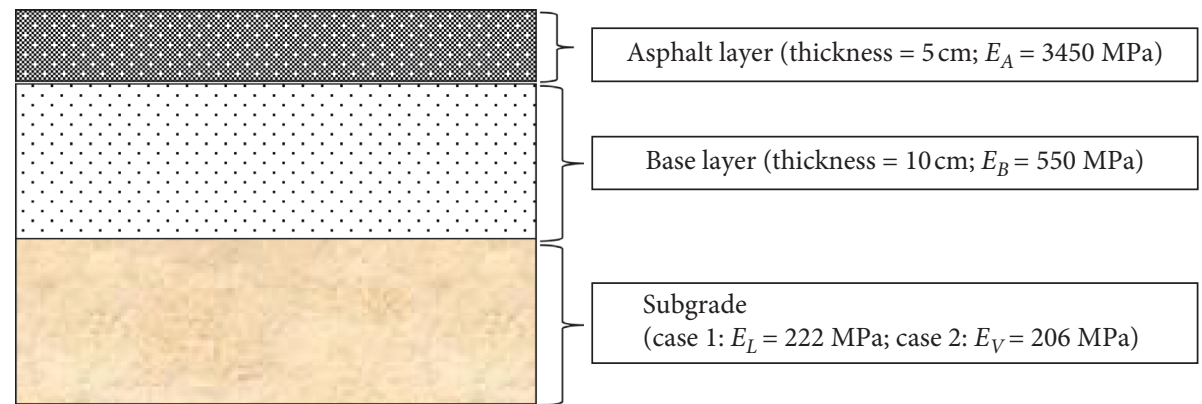

FIgURE 12: Pavement section. Note: EA is the elastic modulus of the asphalt layer; EB is the elastic modulus of the base layer; EL is the average modulus (U1-U10) back-calculated by LEM; EV is the average modulus (U1-U10) back-calculated by VEM.

TABle 2: Design data.

\begin{tabular}{lccc}
\hline Parameters & Value & Parameters & Value \\
\hline Length of analysis & 20 & Initial ADT (vehicles/day) & 800 \\
Design confidence level (95\%) & $\mathrm{C}$ & Final ADT (vehicles/day) & 1200 \\
Initial serviceability index & 4.5 & Total 80 kN ESALs (millions) & 0.8 \\
Final serviceability index & 2.5 & Percentage of truck in ADT & $7 \%$ \\
\hline
\end{tabular}

TABle 3: Coefficients for determining the cracking life.

\begin{tabular}{|c|c|c|c|}
\hline Agency & $f_{1}$ & $f_{2}$ & $f_{3}$ \\
\hline Asphalt Institute & 0.0796 & 3.291 & 0.854 \\
\hline Shell equation & 0.0685 & 5.671 & 2.363 \\
\hline Transport and road research laboratory (TRRL) & $1.66 \times 10^{-10}$ & 4.320 & 0 \\
\hline
\end{tabular}

A significant reduction in the design life was observed if the soil modulus of upper embankment obtained from the VEM were used instead of that obtained from the LEM. In this case study, the soil moduli obtained from the LEM and VEM are $222 \mathrm{MPa}$ and $206 \mathrm{MPa}$, respectively. The Asphalt Institute, Shell, and TRRL methods were used for the analysis, which showed that with a reduction of $8 \%$ in the soil modulus, the cracking life measure by the aforementioned three methods decreased by $12.6 \%, 20.8 \%$, and $15.5 \%$, respectively.

5.2. Rutting Criteria. Rutting, a common phenomenon of flexible pavement, is indicated by the permanent deformation or rut depth that occurs along the wheel paths. 


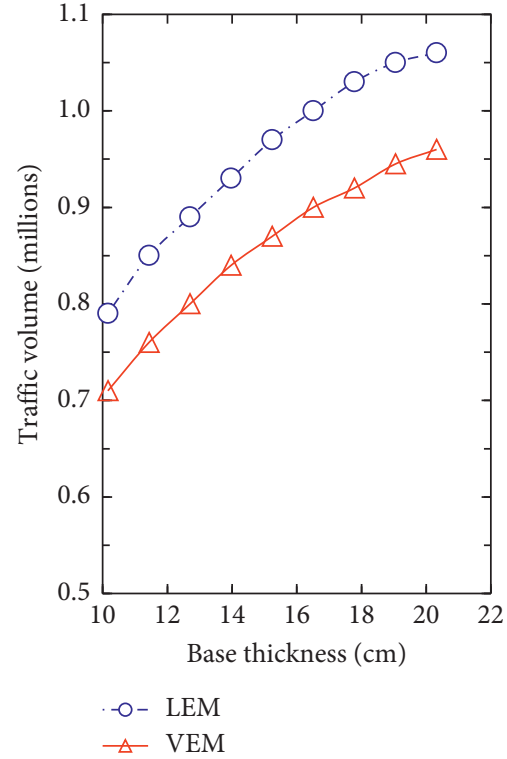

(a)

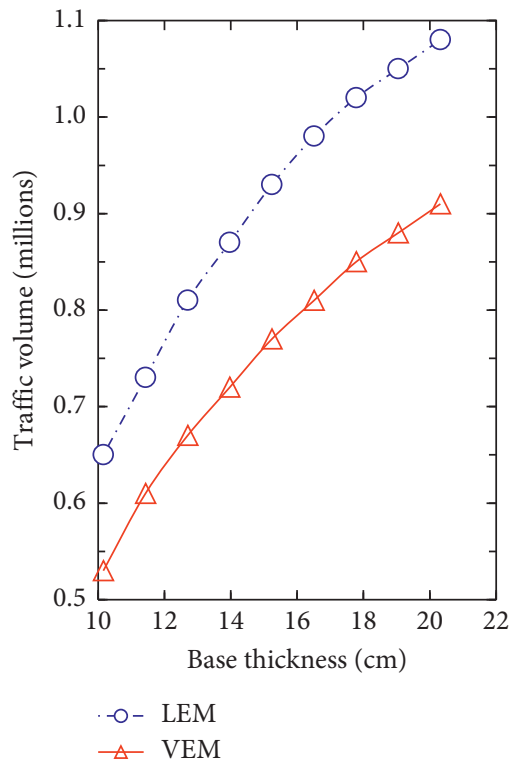

(b)

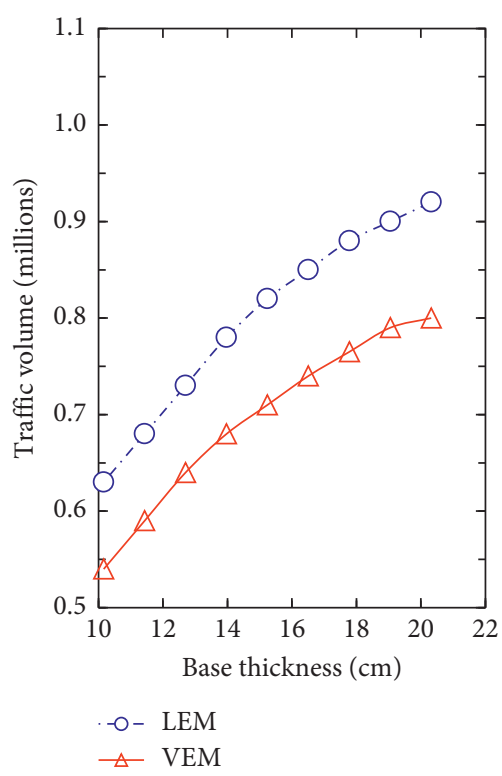

(c)

FIgURE 13: Fatigue cracking life of flexible pavement. (a) Asphalt Institute method. (b) Shell method. (c) TRRL method.

TABLE 4: Coefficients for determining the rutting life.

\begin{tabular}{lcr}
\hline Agency & $f_{4}$ & $f_{5}$ \\
\hline Asphalt Institute & $1.36 \times 10^{9}$ & 4.477 \\
Shell (95\% reliability) & $1.05 \times 10^{-7}$ & 4.000 \\
UK transport and road research (UTRR) & $6.18 \times 10^{-8}$ & 3.950 \\
\hline
\end{tabular}

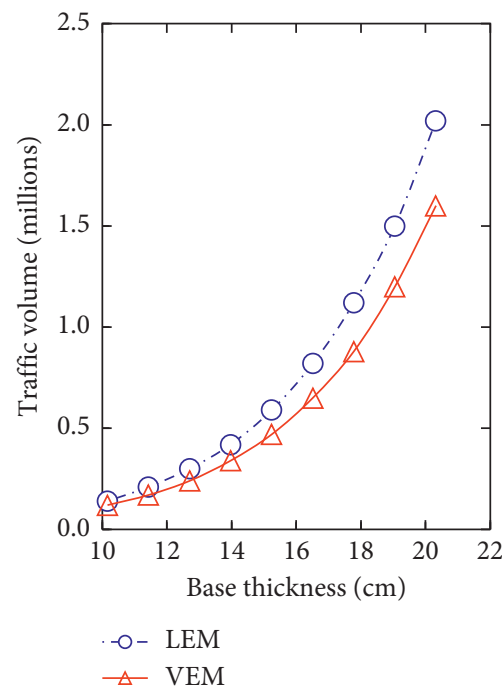

(a)

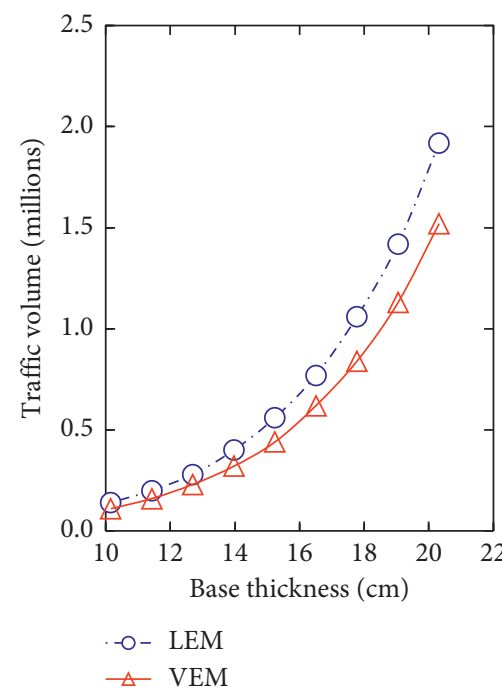

(b)

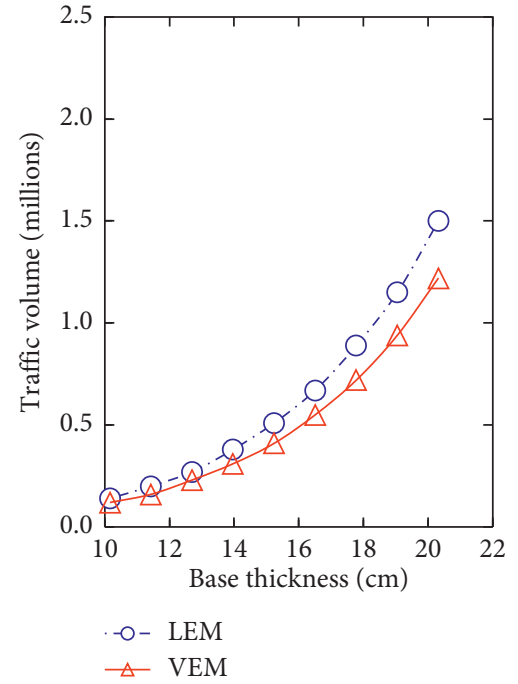

(c)

FIgUre 14: Rutting life of flexible pavement. (a) Asphalt Institute method. (b) Shell method. (c) UTRR method.

Design life $\left(N_{d}\right.$ : allowable load repetition) can be calculated by the following equation:

$$
N_{d}=f_{4}\left(\varepsilon_{v}\right)^{-f_{5}},
$$

where $\varepsilon_{v}$ is the vertical compressive strain acting on the top of subgrade layer and $f_{4}$ and $f_{5}$ are constant values proposed by different agencies that are listed in Table 4 . 
The rutting life obtained from these methods is shown in Figure 14.

The compressive strain acting on the top of the subgrade layer is directly related to the soil modulus of upper embankment and the thickness of the base layer. Reducing the soil modulus led to an increase in the vertical strain, which eventually reduced the pavement rutting life. With a reduction of $8 \%$ in the soil modulus, the pavement rutting life decreased by $25 \%$ (base thickness $=15 \mathrm{~cm}$ ). Based on the Asphalt Institute's method, when the Shell and UTRR methods were used, the rutting life decreased by $18.4 \%$ and $19.6 \%$, respectively.

\section{Conclusions}

In this study, based on the viscoelastic model, a modulus back-calculation method was proposed to estimate the static soil modulus which used the load-deflection/time-history data under the impact load. The effectiveness of the VEM was verified by the in situ PFWD and PLT performed on low and high stiffness soil layers. The effect of moduli obtained from the LEM and VEM on the pavement performance was investigated through a hypothetical case study. The following conclusions can be drawn:

(1) Under an impact load, the peak value of deflections lags behind the peak value of load, and the viscoelastic hysteresis of load-deflection curve is noticeable. The subgrade has significant deformation hysteresis and load-displacement nonlinearity.

(2) The nonlinear dynamic response characteristic of soil was ignored by the LEM, and the modulus was overestimated. For a stiffer soil $(>200 \mathrm{MPa})$, the average error is around $12 \%$, but for low stiffness soil $(<25 \mathrm{MPa})$, the average error is more than $50 \%$. The average error of LEM decreases with the increase in soil modulus.

(3) The loading frequency for the PLT is $0 \mathrm{~Hz}$. However, a frequency of about $4 \mathrm{~Hz}$ was used by the LEM, which led to the overestimation of modulus. This frequency has certain influence on the measurement and back-calculation of soil modulus.

(4) The VEM of PFWD modulus back-calculation can reflect the nonlinear dynamic response characteristic of soils. It can also calculate the static modulus by incorporating the dynamic load data. For a stiffer soil, the average error is less than 5\%; for the low stiffness soil, the average error is less than $15 \%$.

(5) Pavement analysis in the hypothetical case study shows that compared with the modulus obtained from the VEM, the modulus obtained from the LEM overestimates the fatigue-cracking and rutting life of flexible pavement.

\section{Data Availability}

The data used to support the findings of this study are included within the article.

\section{Conflicts of Interest}

The authors declare that they have no conflicts of interest.

\section{Acknowledgments}

The authors wish to acknowledge the financial support of the Natural Science Foundation of China (51108049) and Highway Industry Standard Compilation Project of Ministry of Transportation (JTG-201507).

\section{References}

[1] J. G. Grasmick, M. A. Mooney, R. W. Surdahl, M. Voth, and C. Senseney, "Capturing a layer response during the curing of stabilized earthwork using a multiple sensor lightweight deflectometer," Journal of Materials in Civil Engineering, vol. 27, no. 6, Article ID 04014183, 2015.

[2] M. A. Mooney and P. K. Miller, "Analysis of lightweight deflectometer test based on in situ stress and strain response," Journal of Geotechnical and Geoenvironmental Engineering, vol. 135, no. 2, pp. 199-208, 2009.

[3] A. J. Puppala, Estimating Stiffness of Subgrade and Unbound Materials for Pavement Design, The National Academies Press, Washington, DC, USA, 2008.

[4] C. T. Senseney, R. A. Krahenbuhl, and M. A. Mooney, "Genetic algorithm to optimize layer parameters in light weight deflectometer backcalculation," International Journal of Geomechanics, vol. 13, no. 4, pp. 473-476, 2013.

[5] D. H. Stamp and M. A. Mooney, "Influence of lightweight deflectometer characteristics on deflection measurement," Geotechnical Testing Journal, vol. 36, no. 2, pp. 216-226, 2013.

[6] J. Zhang, F. Gu, and Y. Zhang, "Use of building-related construction and demolition wastes in highway embankment: laboratory and field evaluations," Journal of Cleaner Production, vol. 230, pp. 1051-1060, 2019.

[7] J. G. Grasmick, M. A. Mooney, C. T. Senseney, R. W. Surdahl, and M. Voth, "Comparison of multiple sensor deflection data from lightweight and falling weight deflectometer tests on layered soil," Geotechnical Testing Journal, vol. 38, no. 6, pp. 851-863, 2015.

[8] D.-F. Lin, C.-C. Liau, and J.-D. Lin, "Factors affecting portable falling weight deflectometer measurements," Journal of Geotechnical and Geoenvironmental Engineering, vol. 132, no. 6, pp. 804-808, 2006.

[9] A. Benedetto, F. Tosti, and L. Di Domenico, "Elliptic model for prediction of deflections induced by a light falling weight deflectometer," Journal of Terramechanics, vol. 49, no. 1, pp. 1-12, 2012.

[10] P. R. Fleming, M. W. Frost, and J. P. Lambert, "Review of lightweight deflectometer for routine in situ assessment of pavement material stiffness," Transportation Research Record, vol. 2004, no. 1, pp. 80-87, 2008.

[11] M. Frost, P. Fleming, and J. Lambert, "Lightweight deflectometers for quality assurance in road construction," in Proceedings of the 8th International Conference on the Bearing Capacity of Roads, Railways and Airfields, Champaign, IL, USA, 2009.

[12] E. Pan, A. Sangghaleh, and A. Molavi, An Efficient and Accurate Genetic Algorithm for Backcalculation of Flexible Pavement Layer Moduli, Department of Transportation, Research and Development, Columbus, OH, USA, 2012.

[13] C. T. Senseney and M. A. Mooney, "Characterization of twolayer soil system using a lightweight deflectometer with radial 
sensors," Transportation Research Record: Journal of the Transportation Research Board, vol. 2186, no. 1, pp. 21-28, 2010.

[14] D. J. White and P. K. R. Vennapusa, "In situ resilient modulus for geogrid-stabilized aggregate layer: a case study using automated plate load testing," Transportation Geotechnics, vol. 11, pp. 120-132, 2017.

[15] A. K. Appea, "Validation of FWD testing results at the virginia smart road: theoretically and by instruent responses, Ph.D. Dissertation," Virginia Polytechnic Institute and State University, Blacksburg, VA, USA, 2003.

[16] R. Lytton, "Backcalculation of pavement layer properties," in Nondestructive Testing of Pavements and Backcalculation of Moduli, Vol. 7-38, ASTM International, West Conshohocken, PA, USA, 1989.

[17] A. Nega, H. Nikraz, and I. L. Al-Qadi, "Dynamic analysis of falling weight deflectometer," Journal of Traffic and Transportation Engineering (English Edition), vol. 3, no. 5, pp. 427-437, 2016.

[18] American Society for Testing and Materials, ASTM D5858-96 Standard Guide for Calculating in Situ Equivalent Elastic Moduli of Pavement Materials Using Layered Elastic Theory, Vol. 1, American Society for Testing and Materials, West Conshohocken, PA, USA, 2015.

[19] Y. H. Huang, Pavement Analysis and Design, Pearson/Prentice Hall, Upper Saddle River, NJ, USA, 2nd edition, 2004.

[20] C. Asli, Z.-Q. Feng, G. Porcher, and J.-J. Rincent, "Backcalculation of elastic modulus of soil and subgrade from portable falling weight deflectometer measurements," Engineering Structures, vol. 34, pp. 1-7, 2012.

[21] H. N. Amir and A. Javad, "Explicit dynamic analysis using dynamic relaxation method," Computers and Structures, vol. 175, pp. 91-99, 2016.

[22] S. Hudsadin and S. Yasothorn, "Dynamic soil models for backcalculation of material properties from falling weight deflectometer deflection data," Procedia Engineering, vol. 189, pp. 152-157, 2017.

[23] M. Ameri, M. Malakouti, and P. Malekzadeh, "Quasi-static analysis of multilayered domains with viscoelastic layer using incremental-layerwise finite element methodfinite element method," Mechanics of Time-dependent Materials, vol. 18, no. 1, pp. 275-291, 2014.

[24] Y. A. Ahmet, K. Fethi, and T. Gulcin, "Quasi-static and dynamic analysis of viscoelastic plates," Mechanics of Timedependent Materials, vol. 19, pp. 483-503, 2015.

[25] American Society for Testing and Materials, ASTM D698-12e2 Standard test methods for laboratory compaction characteristics of soil using standard effort (12 $400 \mathrm{Ft}-\mathrm{lbf} / \mathrm{ft} 3(600 \mathrm{KN}-\mathrm{m} /$ $\left.\mathrm{m}^{3}\right)$ ), American Society for Testing and Materials, West Conshohocken, PA, USA, 2012.

[26] American Society for Testing and Materials, ASTM D1557$12 e 1$ Standard test methods for laboratory compaction characteristics of soil using modified effort (56,000 ft-lbf/Ft3 $\left(2700 \mathrm{kN}-\mathrm{m} / \mathrm{m}^{3}\right.$, American Society for Testing and Materials, West Conshohocken, PA, USA, 2012.

[27] American Association of State Highway and State Highway Officials, AASHTO T307-99 Standard Method of Test for Determining the Resilient Modulus of Soils and Aggregate Materials, American Association of State Highway and State Highway Officials, Washington, DC, USA, 2003.

[28] American Society for Testing and Materials, ASTM E2583-07 Standard Test Method for Measuring Deflections with a Light Weight Deflectometer (LWD), American Society for Testing and Materials, West Conshohocken, PA, USA, 2007.
[29] American Society for Testing and Materials, ASTM D1195-93 Standard Test Method for Repetitive Static Plate Load Tests of Soils and Flexible Pavement Components, for Use in Evaluation and Design of Airport and Highway Pavements, American Society for Testing and Materials, West Conshohocken, PA, USA, 2007.

[30] S. D. Guzzarlapudi, V. K. Adigopula, and R. Kumar, "Comparative studies of lightweight deflectometer and Benkelman beam deflectometer in low volume roads," Journal of Traffic and Transportation Engineering (English Edition), vol. 3, no. 5, pp. 438-447, 2016. 


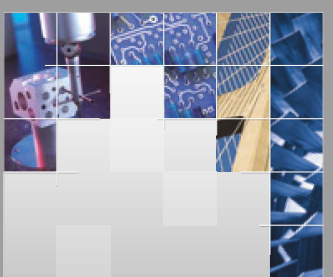

\section{Enfincering}
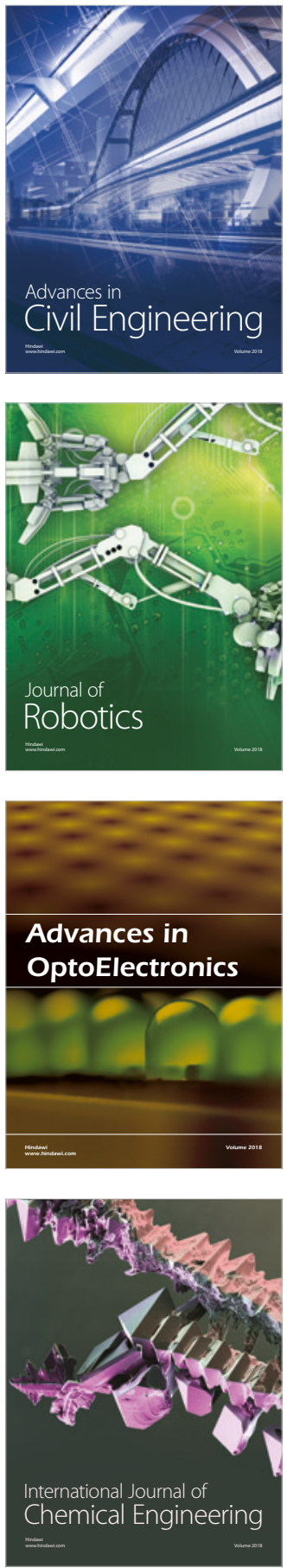

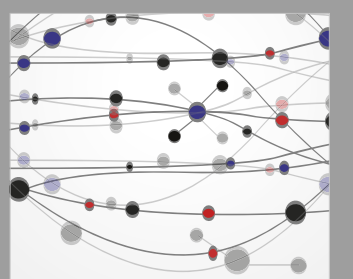

\section{Rotating \\ Machinery}

The Scientific World Journal

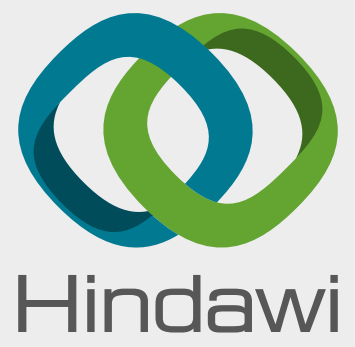

Submit your manuscripts at

www.hindawi.com
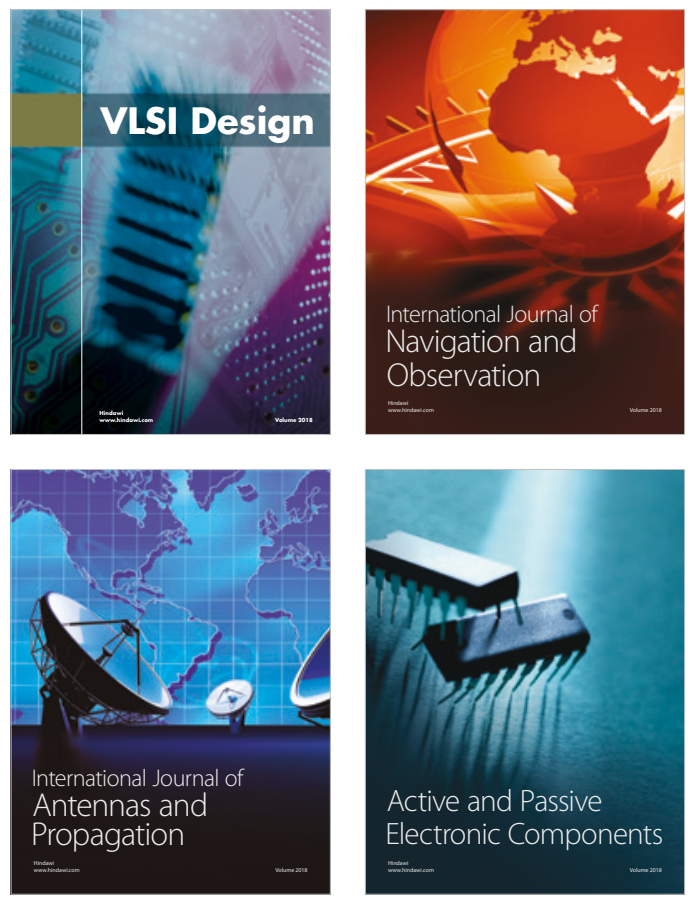
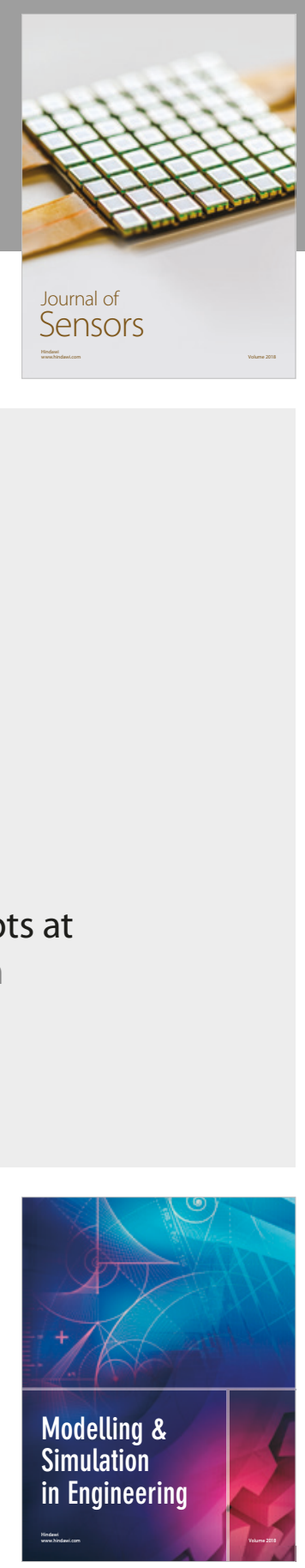

\section{Advances \\ Multimedia}
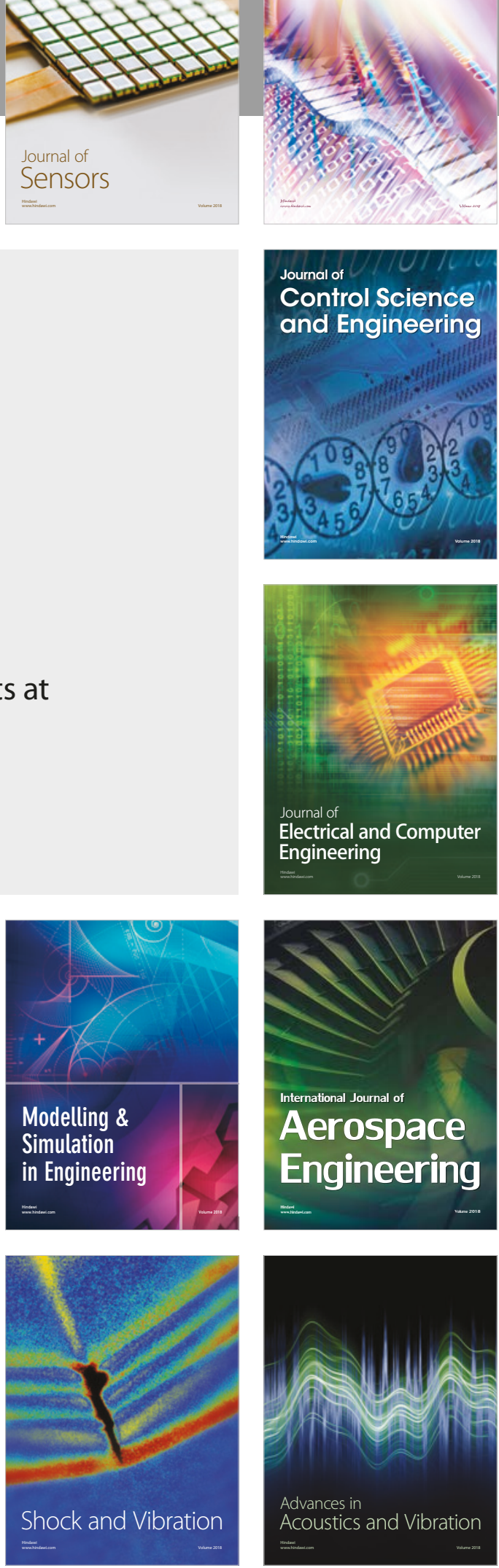